\title{
ANALISIS BENTUK KESALAHAN PADA KALIMAT ILL-FORMED DAN EFEK KONTEKS PADA INFERENSI
}

\author{
Nyi Raden Nuraini Siti Fathonah, SS.,M.Hum \\ Program Studi Teknik Informatika, Politeknik Pos Indonesia \\ Email : nuraini@poltekpos.ac.id
}

\begin{abstract}
Abstrak
Kalimat ill-formed atau kalimat yang tidak sesuai dengan tata bahasa acapkali muncul di dalam tuturan pembelajar Bahasa Inggris,khususnya tuturan mahasiswa di sebuah politeknik swasta Bandung.. Dari hasil penelitian ini didapati kesalahan pembelajar Bahasa Inggris berupa penghilangan (omission), penambahan (addition), dan kesalahan bentuk (misformation). Penelitian terhadap kesalahan kalimat Bahasa Inggris sudah sering di-publish, namun belum ada penelitian yang menyertakan efek konteks terhadap pemahaman kalimat berstruktur kalimat yang salah.Kesalahan kalimat dapat terjadi pada level semantik, morfologi, pragmatik atau sintaksis. Dari penelitian terungkap fakta kalimat Ill-formed yang masih dapat dimengerti adalah kalimat yang tidak ada morfem gramatikal serta efek konteks fisik, epistemis dan linguistik yang dapat membantu pemahaman tuturan ill-formed mahasiswa.

Dengan menggunakan tiga percakapan pembelajar dengan penutur Bahasa Inggris dari Jepang, Belanda dan Rusia penulis menganalisis efek konteks yang membantu inferensi pendengarnya. Kemunculan efek konteks yang membantu inferensi tuturan dari yang paling dominan adalah konteks fisik (64\%) diikuti oleh konteks linguistik (29\%) hingga efek konteks yang jarang muncul yaitu epistemis $(7 \%)$.

Untuk bentuk ill-formed yang muncul terdapat misformation dengan prosentase $60 \%$ dari jumlah tuturan ill-formed (15 kali) sehingga percakapan berlangsung tidak efisien karena ada pengulangan. Sementara itu kesalahan penghilangan (8\%) sebanyak 2 kali. Penyebab kealahan pembelajar yang signifikan adalah false concept hypothesized yaitu $27 \%$.
\end{abstract}

Kata Kunci: Ill-formed, misformation, konteks, inferensi, efek konteks.

\begin{abstract}
Ill-formed sentences or sentences that are not in accordance with grammar often appear in the speech of English learners, especially the speech of students at a private polytechnic in Bandung. From the results of this study found the error of English learners in the form of omission, addition, and form errors (misformation). Research on English sentence errors has often been published, but no research has included context effects on sentence comprehension with the wrong sentence structure. Sentence errors can occur at semantic, morphological, pragmatic or syntactic levels. From the research revealed the facts of Ill-formed sentences that can still be understood are the sentences that have no grammatical morpheme and the effects of physical, epistemic and linguistic contexts that can help students understand ill-formed speech.

By using three conversation learners with English speakers from Japan, the Netherlands and Russia the author analyzes the context effects that help the audience's inference. The emergence of context effects that help speech inference from the most dominant is the physical context (64\%) followed by the linguistic context (29\%) to the rarely emergent context effects that are epistemic (7\%).

For the ill-formed form that appears there is a misformation with a percentage of $60 \%$ of the amount of speech ill-formed (15 times) so that the conversation goes inefficient because
\end{abstract}


there is a repetition. Meanwhile, omission errors (8\%) twice. The significant cause of learning errors was a hypothesized false concept of $27 \%$.

Keywords: Ill-formed, misformation, context, inference, context effects.

\section{Pendahuluan}

Kalimat ill-formed atau kalimat yang tidak sesuai dengan tata bahasa merupakan kesalahan yang biasa dilakukan pembelajar bahasa. Hal ini sesuai dengan pendapat Elis (1991:9) bahwa kalimat pembelajar bahasa mengandung kesalahan. Namun, kesalahan dalam pembelajaran bahasa merupakan sesuatu yang tidak dapat dihindari (Corder, 1984:25).

Beberapa pendapat seputar penyebab terjadinya kalimat ill-formed dan perlu diketahui pengajar bahasa adalah karena pembelajar sering berpikir menggunakan skemata struktur Bahasa Indonesia (bahasa asal) saat mereka menyusun kata berbahasa Inggris (Ritonga, 2009), karena kecerobohan (Norish, 1979:21), interferensi bahasa pertama (Dulay, et.al., 1981:96), kesalahan bahan ajar yang berdampak pada pengabaian aturan dan penggeneralisasian aturan sintaksis yang melebihi tujuan berbahasa itu sendiri (Yoshioka, 2003), bahasantara, dan karena berbicara tanpa persiapan sehingga terjadi language learner slips.

Dari sebab-sebab tersebut, adalah wajar jika kalimat $l l$-formed terdapat pada tuturan Bahasa Inggris mahasiswa politeknik tersebut. Penyebab munculnya kalimat ill-formed pada mahasiswa politeknik ini adalah penggeneralisasian aturan sintaksis dan kecerobohan.

Dalam upaya pengembangan kemampuan Bahasa Inggris, para dosen Bahasa Inggris di politeknik ini berupaya memberikan tugas yang dapat mengeksplorasi kemampuan mahasiswa. Salah satu kegiatan yang dijadikan tugas mereka adalah mewawancarai orang asing. Sebelum penugasan wawancara, dalam mata kuliah Bahasa Inggris mahasiswa sudah diberikan materi terkait perkenalan, dan negara di dunia. Mereka sudah diberikan latihan pertanyaan-jawaban dengan topik yang relevan. Pada intinya dengan melalui penugasan wawancara itu, mahasiswa dilatih untuk memahami tuturan lawan bicara, belajar bagaimana menimpali tuturan lawan bicara dan menerapkan ajaran struktur kalimat Bahasa Inggris yang mereka dapatkan di kelas.

\section{Penelitian Terkait}

Penelitian dengan kalimat ill-formed sebagai objeknya sudah dilakukan sebelumnya dan lebih banyak didominasi penganalisisan dengan aplikasi komputer. Salah satunya penelitian Weischedel, Ralph.,et.al (1983). Mereka mengajukkan meta rules dan struktur kendali yang digunakan untuk memproses input yang ill-formed secara sintaktis, semantis, leksikal ataupun pragmatis. Pembahasan mereka berkisar pemrosesan input ll-formed dengan sistem komputerisasi.

Penelitian Foster-Cohen (2004) hampir serupa dengan penelitian penulis, yakni penggunaan interaksi antara native speaker dan non native speaker. Di dalam penelitian mereka, Teori Relevansi Sperber dan Wilson digunakan untuk menangkap interaksi antara kedua penutur .

Penelitian tentang efek konteks terhadap pemahaman tuturan ill-formed Bahasa Inggris belum pernah dilakukan, , maka dalam jurnal penelitian ini penganalisisan efek konteks terhadap inferensi tuturan ill-formed pembelajara Bahasa Inggris. Dengan demikian penganalisisan efek konteks pada tuturan ill-formed Bahasa Inggris ini menjadi salah satu perumusan masalah penelitian ini, mengingat karena kesalahan tuturan mahasiswa terjadi 
secara sistematis dan melibatkan proses kognitif mahasiswa saat mereka merekonstruksi bahasa baru.

Penulis merumuskan masalah-masalah ke dalam pertanyaan penelitian sebagai berikut:

1. Bentuk ill-formed apakah yang terjadi pada tuturan mahasiswa di sebuah politeknik swasta Bandung pada saat mereka bertanya-jawab dengan penutur asing?

2. Konteks apa yang membantu pendengar dalam menginferensi kalimat ill-formed mahasiswa tersebut?

3. Jenis kesalahan tuturan mahasiswa apa saja yang masih dapat dipahami pendengarnya? Adapun tujuan penelitian dalam jurnal ini adalah:

1. Untuk mengetahui bentuk ill-formed yang terdapat di tuturan mahasiswa Politeknik Pos Bandung ketika bertanya-jawab Bahasa Inggris dengan penutur asing sehingga dapat dicari penyebabnya dan solusinya.

2. Untuk mengetahui jenis konteks yang membantu pendengar di dalam menginferensi kalimat ill-formed mahasiswa.

3. Untuk mengetahui jenis kesalahan yang masih dapat dipahami oleh pendengar.

\section{Metode Penelitian}

Penelitian dalam jurnal ini menggunakan metode kualitatif dan kuantitatif. Kualitatif berarti data yang dikumpulkan bukan berupa angka, melainkan berupa rekaman video di lapangan dan transkrip percakapan, sedangkan metode kuantitatif datanya berupa angka.

Penulis mengumpulkan data rekaman hasil interview mahasiswa Politeknik Pos Indonesia dengan orang asing dan menganalisis tuturan ill-formed secara deskriptif. Dari pengamatan maupun penganalisisan, diharapkan ada temuan penyebab kesamaan pemahaman maupun kesalahpahaman.

Untuk menganalisis kesalahan diperlukan suatu prosedur. Terdapat 4 (empat) langkah prosedur analisis kesalahan berbahasa, yakni; pengumpulan data, pengidentifikasian kesalahan, penjelasan kesalahan, pengklasifikasian kesalahan, dan pengevaluasian kesalahan,

\section{Tinjauan Pustaka}

Sesuai dengan judul penelitian, maka perlu dijelaskan apa itu kalimat ill-formed, konteks,efek konteks, dan inferensi.

Ill-formed adalah suatu input yang melanggar batasan normatif suatu sistem (Weischedel, 1983); ungrammatical (htttp://www.artikata.com/arti-93034-ill-formed.htm) atau tak gramatikal, yang berarti 1) tidak dibenarkan oleh kaidah tata bahasa; 2) tak sesuai dengan konvensi morfologis atau sintaksis suatu bahasa; 3) tidak terterima oleh bahasawan (Kridalaksana, 1993:207). Kalimat ill-formed yang dianalisis dalam jurnal ini adalah kalimat ill-formed Bahasa Inggris.

Pembelajar bahasa yang membuat kalimat ill-formed berupaya agar komunikasi tetap lancar. Pada proses pembelajaran Bahasa Inggris, sering terjadi alih kode, yaitu penggunaan Bahasa Indonesia di sela-sela percakapan. Pembelajar pada umumnya mengulangi ucapannya dengan kalimat lain supaya ditanggapi oleh pendengarnya dan agar tidak terjadi salah paham. Hal ini sesuai dengan pendapat Wilks (1976) bahwa kalimat ill-formed masih dapat dipahami oleh pendengarnya dengan mengusahakan berbagai upaya.

Memahami tuturan ill-formed menurut Gabrielatos (1999) bisa menggunakan konteks umum, skemata (knowledge of the world). Dari sumber lain disebutkan bahwa kita bisa menanyakan kembali kepada si penutur jika kurang jelas apa maksudnya. Pemahaman dikatakan gagal jika inferensi dan maksud yang sebenarnya berbeda sama sekali. 
Konteks adalah aspek-aspek lingkungan fisik atau sosial yang kait-mengait dengan ujaran tertentu, juga pengetahuan yang sama-sama dimiliki pembicara dan pendengar sehingga pendengar paham akan apa yang dimaksud pembicara (Kridalaksana, 1993:120). Konteks beragam jenisnya dan mencakup sisi linguistis, sintaksis, situasi dan budaya. Efek konteks adalah implikasi kontekstual (Xiao-Hui,2010). Yang termasuk di dalam efek konteks adalah efek informasi, efek interpersonal, dan sebagainya. Menurut Sperber dan Wilson (1986) efek konteks merupakan hasil interaksi informasi baru dan lama atau 'kontekstualisasi'. Konteks lama diperbaiki atau ditambah untuk menjadi basis tahap komunikasi selanjutnya (efek konteks baru) dan penginferensian. Unsur luar kalimat seperti suara (voice) dan tubuh (body) diperlukan juga agar makna kalimat menjadi mantap.

Konteks penting untuk memahami tuturan, memahami maksud penutur. Konteks meliputi tuturan sebelumnya, posisi penutur dalam peristiwa tutur, hubungan antar penutur, pengetahuan, tujuan, setting sosial dan aspek fisik peristiwa tutur (Cruise, 2006: 136),kontek fisik, konteks epistemis (kesamaan latar belakang atau pengetahuan pembicara/pendengar), konteks linguistis dan konteks sosial menurut Syafi'ie (1990:126). Penjelasan dan contohcontohnya adalah sebagai berikut:

a. Konteks fisik yang meliputi tempat terjadinya pemakaian bahasa dalam suatu komunikasi.

Contoh:

A: "Ibu sapi atau domba?."

B: "Sapi."

Percakapan terjadi di masjid saat acara pemotongan hewan kurban. Ibu A ingin tahu apakah Ibu B akan kurban sapi atau domba, yang dijawab oleh Ibu B dengan jawaban 'Sapi'. Adanya konteks fisik (A dan B sama-sama mengerti mereka ada di acara kurban) menjadikan komunikasi lancar. Paham akan konteks pembicaraan dicirikan dengan adanya kesamaan paham antar penutur. Pertanyaan atau jawaban yang pendek menjadi ciri kesamaan paham disebabkan karena mereka berada di dalam konteks yang sama.

b. Konteks epistemis, latar belakang pengetahuan yang sama-sama diketahui oleh penutur dan mitra tuturnya.

Contoh:

A: "MU sudah datang tuh, Bu Nur mau?"

B: "Mau. Dari tadi sudah lapar nih!"

Dari percakapan di atas, A dan B sudah tahu apa atau siapa MU, yang ternyatasingkatan dari Mang Udin, tukang bakso langganan. Percakapan berlangsung lancar karena didukung konteks epistemis.

c. Konteks linguistik yang terdiri atas kalimat-kalimat atau ujaran-ujaran yang mendahului dan mengikuti ujaran tertentu dalam suatu peristiwa komunikasi.

A: "What city did you visit for the first time in Indonesia?"

B: "I visited Yogyakarta. It's an old city but beautiful."

A:"Oh, what did you see there?"

B: "I saw Kraton Yogya."

Percakapan di atas terjadi antara orang Indonesia dengan B (turis asing). A bertanya tentang apa yang dilihat turis itu di Yogya. Jawaban turis sesuai dengan pertanyaan A karena turis itu mengerti kata 'there' mengacu pada kota Yogya. Kota Yogya disebutkan di kalimat sebelumnya.

d. Konteks sosial, relasi sosio-kultural yang melengkapi hubungan antar pelaku atau partisipan dalam percakapan (Syafi'i dalam Lubis, 2011: 60). 
Menurut Blakemore (1998:12) inferensi diartikan deduction atau evidence-based guess. Inferensi merupakan simpulan yang ditarik oleh pembaca tentang hal yang tidak dituturkan berdasarkan apa yang sebenarnya dituturkan. Inferensi dilakukan dengan menggunakan pengetahuan yang dimiliki pendengar, terutama pada tuturan atau teks yang secara implisit memberikan informasi kepada pendengarnya.

Kajian pada jurnal ini juga terkait dengan sintaksis, pragmatis, semantis, makna leksikal dan makna gramatikal.

\section{Pembahasan}

\subsection{Analisis Kesalahan Kalimat}

Data yang digunakan dalam penelitian ini berupa transliterasi dari rekaman video tanyajawab Bahasa Inggris mahasiswa dengan orang asing dari Jepang, Belanda dan Rusia. Pembahasan analisis kesalahan kalimat dilakukan sesuai Prosedur Analisis Kesalahan Berbahasa (Ramlan dalam https://ramlannarie.wordpress.com/2010/05/30/anakes/) agar runtut.

Pada percakapan mahasiswa dengan pelajar Jepang, turis Belanda dan Rusia, terdapat 11 kalimat ill-formed. Berikut adalah beberapa contoh analisis data yang dilakukan :

\section{Korpus 1}

Pelajar 1: "What your job in Bandung?"

\section{(a) Bentuk Ill-Formed}

Kalimat ill-formed yang terjadi pada contoh tuturan 1adalah:

Pelajar $1 \quad$ : "What your job in Bandung?"

Tuturan yang benar adalah:

Pelajar $1 \quad$ : "What is your job in Bandung?"

To be is harus digunakan karena subjek kalimatnya tunggal (your job) (Haryono, 1999:8).

\section{Temuan}

Bentuk ill-formed yang terjadi adalah omission (penghilangan).

\section{(b) Penyebab Ill-Formed}

Penyebab kesalahan Pelajar 1 adalah ignorance of rules restriction.

\section{Korpus 2}

Pelajar 4

Nikita

: "What is city your visited for the first time?"

: "I went to Yogyakarta."

\section{(a)Bentuk Ill-Formed}

Tuturan ill-formed pelajar yang terjadi adalah:

Pelajar $4 \quad$ : What is city your visited for the first time?"

Tuturan yang benar adalah:

Pelajar $4 \quad$ : "What city did you visit for the first time?"

Pada tuturan Pelajar 4 terdapat to be is, sedangkan untuk kalimat verbal, to be is biasanya digunakan sebagai penghubung predikat yang jenis katanya ajektiva,nomina dan adverbia (Hartanto, et.al, 1987:8). Seharusnya ada penggunaan kata kerja bantu did, karena kata kerja bantu did muncul pada struktur kalimat bertanya dan negatif (Hartanto, et.al, 1987:53) kemudian diikuti infinitive (tanpa to) visit. Subjek kalimat di atas seharusnya adalah you, bukan adjective possesive your. Tuturan Pelajar 4 juga menggunakan penggabungan dua tenses, simple present dan simple past.

\section{Temuan}


Penyebab tuturan ill-formed Pelajar 4 adalah misformation.

\section{(b) Penyebab Ill-Formed}

Penyebab misformation adalah overgenerealization, ditandai dengan blend of two structures dan generalisasi berlebihan pada penggunaan is dan your.

\section{Korpus 3}

Pelajar 5 : "Holiday? You are come from is Netherland?"

Eric : "Yea."

Pelajar 5 :"Er...Where are you going?"

Eric : "We went to Jakarta...Bandung ...Yogyakarta...Surabaya. Lombok, and Bali... and back

\section{(a) Bentuk Ill-Formed}

$$
\text { to Amsterdam." }
$$

Kesalahan Pelajar 5 adalah menambahkan are dan is. Kalimat yang benar adalah You come from Netherland, karena verba kalimat adalah come, bukan are atau is.

\section{Temuan}

Bentuk kesalahan tuturan Pelajar 5 adalah addition.

\section{(b) Penyebab Ill-Formed}

Kesalahan Pelajar 5 menunjukkan interlanguage false concept hypothesised karena struktur kalimatnya berbeda dengan struktur Bahasa Indonesia maupun Inggris.

\section{Korpus 4}

Pelajar 2 : "What do you life?"

Masako : "Life?"

Pelajar 2 : "Ya...Live. Tinggal di mana?"

Masako : "Life?"

Pelajar 2 : "Ya."

Masako : "In Indonesia?"

Pelajar $2 \quad$ : "Ya."

Masako :"Ya...in Band... Indonesia the weather is not so cold...not so cold so I like it. Now in Japan it's winter...so cold.

\section{(a) Bentuk Ill-Formed}

Bentuk ill-formed terjadi pada tuturan :

Pelajar 2 : "What do you life? ....Life?"

Tuturan yang benar adalah:

Pelajar $2 \quad$ : "Where do you live?"

Kesalahan Pelajar 2 ditinjau dari aturan sintaksis maupun morfologi. Pertama, bentuk kalimat tanya untuk menanyakan tempat tinggal seharusnya adalah dengan kata tanya where (Hartanto, et.al,1980:34). Kedua, predikat kalimat harus verba (infinitive). Kata life bukan verba, verba yang benar adalah live.

\section{Temuan}

Kesalahan Pelajar 2 adalah misformation.

\section{(b) Penyebab Ill-Formed}

Pada kalimat (1) kalimat yang benar adalah 'How long have you stayed in Indonesia?'.Kesalahan dikategorikan omission karena ada penghilangan bagian struktur kalimat. Di samping itu, ekspresi 'How many come to Indonesia?' adalah ekspresi yang salah untuk menanyakan berapa lama seseorang tinggal di Indonesia. tidak dapat diterima dalam aturan tata bahasa Inggris atau ill-formed yang tidak dapat dipahami lawan tutur. 


\subsection{Analisis Efek Konteks}

Ada berbagai kemungkinan bagaimana penutur asing memahami tuturan mahasiswa yang mengandung kesalahan gramatikal ini. Biasanya dalam percakapan lisan, jika masalah grammar dilanggar tidak akan menimbulkan masalah selama kedua pihak saling memahami. Hal itu karena pemahaman, dapat dibantu efek konteks.

Analisis konteks menjadi fokus penelitian ini karena tuturan mahasiswa politeknik swasta ini berkemungkinan berefek konteks.

Dari jumlah keseluruhan kalimat yang mencapai 216 buah, pada satu kalimat yang illformed terkadang mempunyai dua penyebab dan juga dua konteks.

\section{Korpus 1}

Pelajar 1 : "What your job in Bandung?"

Masako : "Job? Ah, I'm studying... Just studying. I'm a scholarship student."

\section{a) Deskripsi Data}

Dialog di atas terjadi antara pelajar dan Masako (nama samaran). Pelajar 1 adalah mahasiswa Politeknik Pos Indonesia, umur 20 tahun. Masako adalah warga negara Jepang yang sedang kuliah Bahasa Indonesia di UNPAD, umur sekitar 23 tahun.

Konteks pembicaraan adalah tentang pekerjaan Masako. Pembicaraan berlangsung pada pukul 09.00 WIB di sekitar Jalan Layang Pasupati Bandung yang dilalui kendaraan.

\section{b)Efek Konteks}

Tuturan Pelajar 1 masih dapat dipahami oleh Masako meskipun ada penghilangan is. Penghilangan kata bermakna gramatikal biasanya tidak berpengaruh pada pemahaman tuturan. Masako masih dapat memahami pertanyaan dari kata-kata: what, your, dan job.

\section{c)Temuan}

Pemahaman Masako terhadap tuturan Pelajar 1 dibantu oleh konteks fisik.

\section{Korpus 2}

Pelajar $4 \quad$ : "What is city your visited for the first time?"

Nikita : "I went to Yogyakarta."

\section{Deskripsi Data}

Percakapan terjadi antara Pelajar 4 dan Nikita. Pelajar 4 adalah mahasiswa Politeknik Pos, umur 20 tahun. Nikita adalah turis mancanegara dari Rusia, berumur 25 tahun.

Konteks pembicaraan adalah kota di Indonesia yang pertama kali dikunjungi Nikita. Percakapan berlangsung di Botanical Mall Bogor pada pukul 17.00 WIB.

\section{Efek Konteks}

Tuturan ill-formed Pelajar 4 ini direspon Nikita dengan menjawab,"I went to Yogyakarta." Karena jawaban Nikita sesuai dengan harapan, hal ini menunjukkan tuturan ill-formed Pelajar 4 masih dapat dipahami karena dia memahami kata yang bermakna leksikal yaitu city, you, visit, first dan time.

\section{Temuan}

Nikita menginferensi tuturan Pelajar 4 dengan bantuan konteks fisik.

\section{Korpus 3}

Pelajar 5 : "Holiday? You are come from is Netherland?"

Eric : "Yea."

Pelajar 5 :"Er...Where are you going?" 
Eric : "We went to Jakarta...Bandung ...Yogyakarta...Surabaya. Lombok, and Bali... and back

$$
\text { to Amsterdam." }
$$

\section{Deskripsi Data}

Dialog terjadi antara Pelajar 5 dan Eric. Pelajar 5 adalah mahasiswa sebuah politeknik swasta Bandung berumur 20 tahun. Eric adalah turis dari Belanda, umur sekitar 24 tahun.

Konteks pembicaraan adalah liburan Eric dan keluarga di Indonesia. Percakapan berlangsung di Paris Van Java Bandung pada pukul 16.00 WIB. Keadaan cukup ramai pengunjung mall.

\section{Efek Konteks}

Tuturan Pelajar 5 masih dapat dimengerti oleh Eric karena Eric paham arti kata you, come, from dan Netherland.

\section{Temuan}

Konteks yang membantu pemahaman Eric adalah konteks fisik.

\section{Korpus 4}

Pelajar 2

Masako

Pelajar 2

Masako

Pelajar 2

Masako

Pelajar 2

Masako

: "What do you life?"

$$
\text { : "Life?" }
$$

: "Ya...Live. Tinggal di mana?"

$$
\text { : "Life?" }
$$

$$
\text { : "Ya." }
$$

like it. Now in

\section{Deskripsi Data}

$$
\text { : "Ya.," "In Indonesia?" }
$$

:"Ya...in Band... Indonesia the weather is not so cold...not so cold so I

Deskripsi Data sama dengan isi Deskripsi Korpus 1. Pelajar 2 adalah mahasiswa Politeknik Pos Indonesia yang berusia 20 tahun. Konteks pembicaraan yaitu tentang tempat tinggal Masako.

\section{Efek Konteks}

Maksud Pelajar 2 menanyakan tempat tinggal Masako sebenarnya sudah jelas dengan menanyakan 'TInggal di mana?', tetapi pertanyaan Pelajar 2 dianggap Masako menanyakan 'life' atau kehidupan di Indonesia. Kesalahpahaman terjadi karena Pelajar 2 tidak tahu perbedaan live dan life, sehingga dia hanya mengiyakan saja ketika Masako bertanya balik 'Life?'.Jawaban Masako akhirnya menyimpang dari pertanyaan Pelajar 2 karena Masako mengatakan tentang cuaca di Bandung yang dingin sama seperti di Jepang saat musim dingin.

\section{SIMPULAN}

Meskipun percakapan yang terjadi antara mahasiswa dan orang asing tidak terlalu bagus, dari hasilnya dapat terlihat kekurangan dosen, kekurangan mahasiswa, Dampak baik bagi dosen adalah dosen mengetahui kelemahan metode ajarnya selama ini dan dapat terdorong untuk memberikan metode pengajaran yang lebih baik lagi.

Terlihat dari hasil percakapan, pada umumnya, pembelajar hanya fokus bertanya dan kurang fokus mendengarkan. Akibatnya tidak ada interaksi aktif, melainkan hanya sekedar tanya-jawab yang tidak ada kesinambungan antar pertanyaan. Orang asing pada umumnya masih dapat memahami tuturan mahasiswa sepanjang ada kata bermakna leksikal. Adapun penghilangan kata bermakna gramatikal tidak mempengaruhi pemahaman orang asing.

Tipe konteks yang membantu pemahaman/inferensi tuturan didominasi konteks epistemis. Dari hasil rekaman video percakapan, pemahaman siswa tentang latar belakang orang asing, sebagai contoh, mereka mengetahui orang asing itu berasal dari Jepang menyebabkan 
pertanyaan diarahkan tentang boneka Jepang, tentang grup musik dari Jepang. Contoh lainnya, ketika siswa mengetahui orang asing dari Belanda akan berwisata selama bermingu-minggu di Indonesia, siswa menyebutkan tentang Bali.

Untuk upaya menginferensi tuturan ill-formed, orang asing tidak selalu berhasil menginferensi maksud mahasiswa. Untuk menghindari kesalahpahaman, hendaknya siswa memberikan informasi tambahan. Namun, di dalam percakapan mahasiswa membiarkan kesalahan inferensi terjadi.

Penelitian selanjutnya diharapkan dapat dikaitkan dengan perancangan model deteksi kesalahan dengan aplikasi komputer.

\section{Referensi}

Wang, Fengjuan, (2010). "The Necessity of Grammar Teaching”. English Language Teaching, $\underline{3},(2)$.

Dulay, Heidi,dkk. (1982). Language Two. Oxford: Oxford University Press.

Foster, Susan H.,Cohen. (2004). 'Relevance Theory, Action Theory and Second Language Communication Strategies.” Second language Research 20(3). 289-302.

Gabrielatos, Costas. (1999). “Inference; How it Works”. TESOL Greece Newsletter, (64).1015.

Haryono,A. (1999). Tata Bahasa Inggris (Cara Menerjemahkan “apakah”). Jakarta: PT. Grasindo.

Ritonga, Abdul Kadir. (1999). Skemata Struktur Bahasa Indonesia terhadap Kecampingan Bahasa Inggris Pada Mahasiswa Akademi Pariwisata Medan, Kajian Morfosintaksis. Medan: Sekolah Pasca Sarjana Universitas Sumatera Utara:tidak diterbitkan.

Weischedel, Ralph.M. et.al, (1983). Meta Rules as a Basic for Processing Ill-Formed Input. American Journal of Computational Linguistics American Journal of Computational Linguistics, 9, (3-4).

Xiao-hui, Xu, (2010). "Analysis of Teacher Talk on the Basis of Relevance Theory". Canadian Social Science.

Yoshioka, Maki. (2003). Japanese and English Learner's Common Grammar ErrorsPreposition vs Particles. www2.kumagaku.ac.jp 